\title{
Temporal response of ganglion cells of the macaque retina to cone-specific modulation
}

\author{
T. Yeh, ${ }^{*}$ B. B. Lee, and J. Kremers ${ }^{\dagger}$ \\ Department of Neurobiology, Max-Planck Institute for Biophysical Chemistry, 37077 Göttingen, Germany
}

Received July 25, 1994; revised manuscript received September 13, 1994; accepted September 13, 1994

\begin{abstract}
The temporal response of cone inputs to macaque retinal ganglion cells were compared with cone-specific sinusoidal modulation used to isolate each cone type. For all cell types of the parvocellular (PC) pathway, temporal responsivity was similar for short (S)-, middle (M)-, and long (L)-wavelength-sensitive cone inputs, apart from small latency differences between inputs to center and surround. The temporal response resembled that expected from receptor physiology. Responses of cells of the magnocellular pathway to M- or L-cone modulation showed more complex properties indicative of postreceptoral processing. Human psychophysical temporal-sensitivity functions were acquired with S-cone modulation under conditions similar to those for the physiological measurements. Ratios of psychophysical to physiological data from S-cone cells (the only cells that respond to this stimulus) yielded an estimate of the central filter acting upon PC-pathway signals. The filter characteristic could be described by a four-stage low-pass filter with corner frequency $3-5 \mathrm{~Hz}$.
\end{abstract}

\section{INTRODUCTION}

A desire to deduce and compare the temporal properties of different cone types has prompted a number of psychophysical studies. Attempts to isolate cone signals psychophysically have used silent substitution stimuli for the middle (M)- and long ( $\mathrm{L}$ )-wavelength-sensitive cones (see, e.g., Ref. 1) or selective chromatic adaptation (e.g., Ref. 2). The most striking difference reported was a slow temporal response of the short-wavelength-sensitive (S)cone mechanism compared with responses of the $\mathrm{M}$ - and L-cone mechanisms. ${ }^{2-4}$ However, it has become apparent that these approaches are complicated by the presence of multiple postreceptoral pathways (see, e.g., Ref. 5). More recent psychophysical evidence suggests that S-cone pathways can respond to high temporal frequencies (up to $\sim 40 \mathrm{~Hz}){ }^{6,7}$

Current physiological evidence indicates that all three cone types have similar temporal properties. In vitro cone responses to brief flashes are all of similar duration and shape. ${ }^{8}$ Zrenner and Gouras ${ }^{9}$ reported that macaque retinal ganglion cells with excitatory S-cone input respond to flickering blue light up to $40 \mathrm{~Hz}$, suggesting a fast temporal response for the S-cone pathway. Similar results have been obtained in the lateral geniculate nucleus. A study that used white noise as a stimulus and M- and L-cone isolating stimuli ${ }^{10}$ reported similar temporal properties for these cones. Nevertheless, differences in the temporal properties of the cones continue to be postulated to account for psychophysical results. For example, Hamer and Tyler ${ }^{11}$ have suggested that the $\mathrm{M}$ cones are faster than the $\mathrm{L}$ cones at higher adaptation levels.

One goal of the present study was to document the temporal characteristics of the three cones at the ganglion-cell level. In the primate retinogeniculate pathway the parvocellular (PC) pathway contains chromatically opponent cells that receive antagonistic input from the $M$ and the $\mathrm{L}$ cones and also contains cells that receive input from
$\mathrm{S}$ cones opposed by some combination of $\mathrm{M}$ and $\mathrm{L}$ cones. Using silent substitution stimuli, we measured PC-cell responses to modulation of the M, L, or S cone. For comparison, we also recorded responses of magnocellular (MC) pathway cells to M- and L-cone-modulating stimuli.

PC-pathway cells respond to chromatic modulation up to higher frequencies than can be perceived psychophysically, and it is necessary to postulate central low-pass filtering of their signals before psychophysical detection. ${ }^{12,13}$ The second goal of this study was to specify this central filter more precisely. With red-green chromatic modulation, a residual response in the MC pathway is present, ${ }^{14}$ which may contribute to psychophysical detection (e.g., Ref. 15). Modulation of the $\mathrm{S}$ cone does not give a MC-pathway response. ${ }^{16}$ We measured psychophysical S-cone temporal modulation sensitivities under conditions comparable with those of the physiological experiments and compared the physiological with the psychophysical data to yield the filter characteristic.

Part of this study has been presented in abstract form. ${ }^{17}$

\section{METHODS}

\section{A. Animal Preparation}

We recorded from cells in the retinas of macaques $(M$. fascicularis). Details of the animal preparation and recording techniques may be found elsewhere. ${ }^{12}$ Briefly, after an initial injection of ketamine, anesthesia was maintained with isoflurane in a $70 \%: 30 \% \mathrm{~N}_{2}: \mathrm{O}_{2}$ mixture (1-2\% during surgery and $0.5-1.0 \%$ during recording). Local anesthesia was applied at the points of surgical intervention. The EEG and the EKG were continuously monitored as a control for anesthetic depth. Muscular relaxation was maintained by intravenous infusion of gallamine triethiodide $(5 \mathrm{mg} / \mathrm{kg} / \mathrm{h})$ with $3 \mathrm{ml} / \mathrm{h}$ of dextrose Ringer. The end-tidal $\mathrm{PCO}_{2}$ was kept near $4 \%$ by adjustment of the rate and depth of ventilation. Body temperature was maintained near $37.5^{\circ}$. 


\section{B. Stimuli and Calibration}

Stimuli were presented through a Maxwellian-view system modified from that described elsewhere ${ }^{13,15}$ by addition of a blue light source. The light sources were red, green, and blue light-emitting diodes (LED's), with dominant wavelengths of 638,554 , and $468 \mathrm{~nm}$, respectively. For the blue diode a dichroic mirror cut off wavelengths above $\sim 510 \mathrm{~nm}$. Colorimetric purities were 99\%, 97\%, and $96 \%$, respectively. Cell data were obtained from the parafovea $\left(3^{\circ}-10^{\circ}\right)$, and we calibrated the LED's in terms of the $10^{\circ} V_{\lambda}$ function. Since the $2^{\circ}$ and the $10^{\circ}$ functions are similar for 554 and $638 \mathrm{~nm}$, relative luminances of the red and the green LED's were calibrated with foveal heterochromatic flicker photometry (HFP) by a subject whose luminosity function closely matched that of the Judd $^{18}$ observer. For the blue diode observers fixated the center of an annular field (inner diameter $4^{\circ}$, outer diameter $6^{\circ}$ ) and performed heterochromatic flicker photometry between the red and the blue diodes. Averaged results were obtained from six color-normal observers. Calibrations were checked with a Photo-Research Spectrascan meter. Time-averaged retinal illuminances were estimated $^{19}$ to be $1000 \mathrm{Td}$ each for the red and the green LED's and 400 Td for the blue LED. When only the red and the green LED's were used, time-averaged chromaticity had a dominant wavelength of $595 \mathrm{~nm}$ [CIE coordinates $(x, y)=(0.60,0.40)]$. With the blue LED added, CIE coordinates were $(x, y)=(0.48,0.31)$.

The LED's were modulated in intensity by frequency modulation of constant-amplitude pulse train, giving a high degree of linearity over more than a 3-log-unit range. We used temporal frequencies between 0.61 and $52 \mathrm{~Hz}$. Stimulus waveforms were generated by a computer through 12-bit digital-to-analog converters. A circular field of $4.7^{\circ}$ was used in physiological experiments.

To modulate $\mathrm{M}$ and $\mathrm{L}$ cones in isolation in the physiological measurements, we modulated the red and the green diodes in counterphase with modulation depths calculated from the Smith-Pokorny fundamentals ${ }^{20}$ so as to modulate selectively one or the other cone. This calculation was confirmed by tests on deuteranopic and protanopic observers. Cone modulation is expressed as Michelson contrast, $C$, where $C=\left(S_{\max }-S_{\min }\right) /$ $\left(S_{\max }+S_{\min }\right)$, and $S_{\max }$ and $S_{\min }$ correspond to maximum and minimum cone excitations calculated from the cone fundamentals. ${ }^{20,21}$ For selective modulation of the $\mathrm{S}$ cone, the blue and the red LED's were modulated in counterphase with the green LED. The required red-to-blue LED modulation ratio was estimated from the MacLeod-Boynton chromaticity diagram ${ }^{22}$ and was confirmed by control experiments described in Section 3 below. The inhibitory mechanism of S-cone cells sums input from $\mathrm{M}$ and $\mathrm{L}$ cones. ${ }^{23}$ For measurement of its response, the red and the green diodes were modulated in phase, and the blue diode was unmodulated. We took the averaged $\mathrm{M}+\mathrm{L}$-cone contrast to represent the cone modulation for this condition.

\section{Physiological Measurements}

After isolation of a ganglion cell's activity, the cell's receptive field location was plotted on the tangent screen. PC-pathway cells were identified by their sustained responses to different colors. MC-pathway cells were iden- tified by their phasic responses to all colors and their high achromatic contrast responsivity. The tests used were developed during recordings in the lateral geniculate nucleus (e.g., Ref. 24), and usually cell classification was unambiguous. The stimulus was aligned to be centered on the receptive field. At each frequency, responses were measured over a range of cone contrasts. Approximately $6 \mathrm{~s}$ of activity was averaged for each condition. First- and second-harmonic amplitudes were extracted by Fourier analysis.

\section{Psychophysical Measurements}

We measured psychophysical sensitivities to S-cone modulation by using the same device as in the physiological experiments. The observers viewed stimuli foveally through a 3-mm artificial pupil, using chin and forehead rests to maintain stable head position. A $1^{\circ}$ field was used. Light from a Barco monitor provided a $4.7^{\circ}$ surround field 1 log unit lower in luminance than the test field but of the same chromaticity. Without this surround some subjects reported a flickering halo around the test field when the blue LED was modulated, presumably as a result of intraocular light scatter. The CIE coordinates of the test field were $(x=0.40, y=0.31)$, similar to those in the physiological recordings. The mean retinal illuminance was $700 \mathrm{Td}$ for the test stimulus. The values are lower than those in the physiological experiments, so we performed control observations on some cells with S-cone input at $700 \mathrm{Td}$. Only minor differences in temporal properties were observed compared with the higher retinal illuminance.

We determined each observer's tritanopic confusion line by mapping the observer's sensitivities to different combinations of the red, green, and blue lights modulated at $10-20 \mathrm{~Hz}^{25}$ The method used is a temporal analog of the melting-border criterion that is used to determine the tritanopic confusion line in minimal-distinct-border experiments. ${ }^{26}$ The method of adjustment was used to measure S-cone-modulation sensitivities at different frequencies. Values were averaged over five measurements. Four observers (aged 22-47 years) participated in the experiment: two of the authors (TY and BL) and two naive observers (DL and $\mathrm{PD})$. Observer $\mathrm{BL}$ is a deuteranope, and the other three observers are color normal.

\section{RESULTS}

\section{A. Specification of Cone-Isolating Stimuli}

The stimuli used to modulate the $\mathrm{M}$ and the $\mathrm{L}$ cones selectively were calculated on the basis of the Smith-Pokorny ${ }^{20}$ human cone fundamentals and checked on human dichromates. $\mathrm{M}$ - and L-cone absorption spectra are similar in macaque and human, ${ }^{27,28}$ and it is likely that selective modulation of $\mathrm{M}$ - and L-cone inputs was obtained. However, if preretinal absorption at short wavelengths were to differ in the two species, selective modulation of the $\mathrm{S}$ cone might be more difficult to achieve. We therefore performed control experiments to test the S-cone-modulating stimulus. An S-cone-modulating stimulus for the parafovea of a human observer was calculated as described in Section 2. We tested this stimulus on MC 

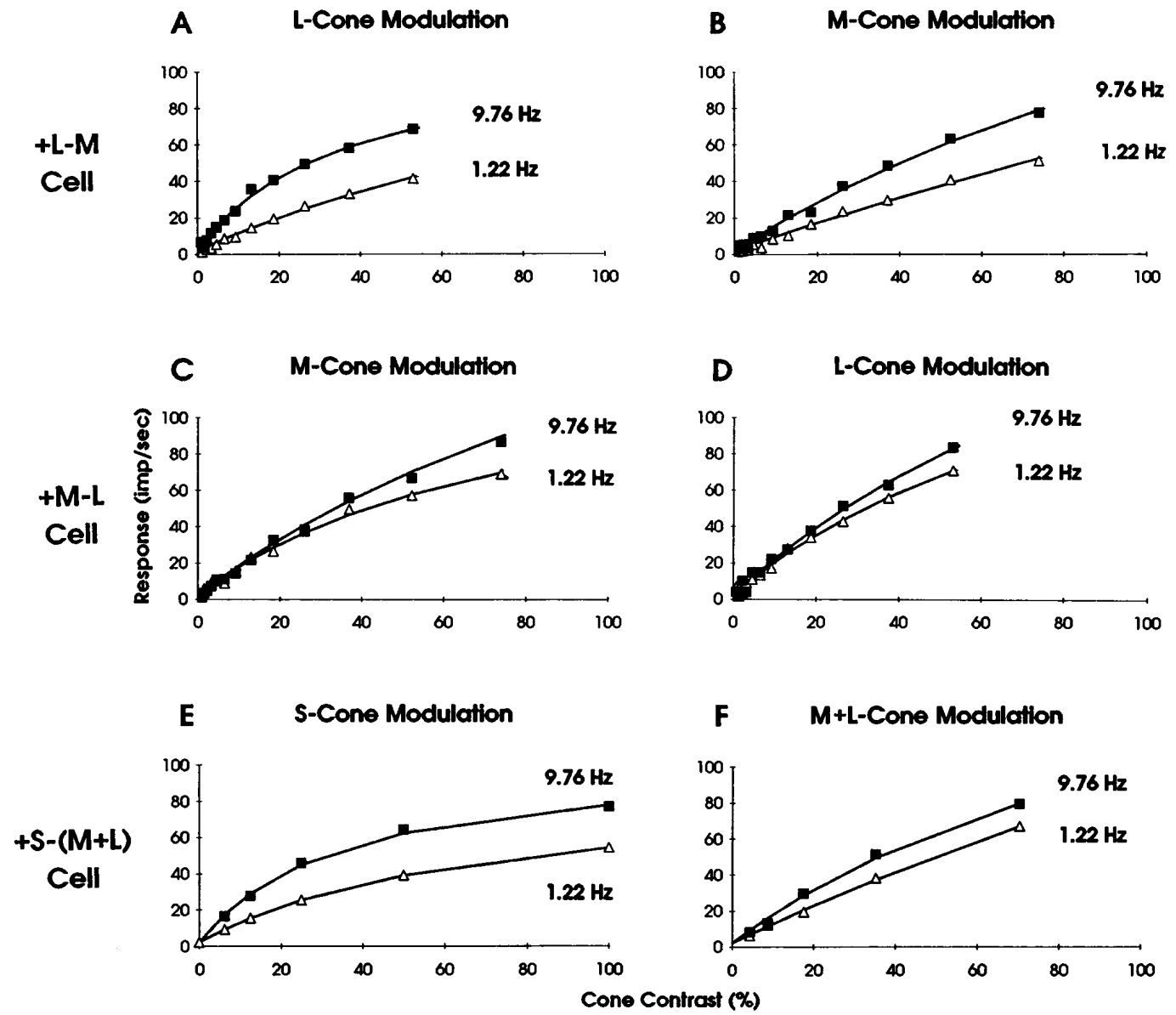

Fig. 1. Cone-contrast response functions: A, B, First-harmonic amplitude of responses to L- and M-cone modulation, respectively, for a PC-cell with $+\mathrm{L}-\mathrm{M}$ cone input; $\mathrm{C}, \mathrm{D}$, responses to $\mathrm{M}$ - and L-cone modulation for a PC cell with $+\mathrm{M}-\mathrm{L}$ cone input; E, F, responses to S- and combined M- and L-cone modulation for a cell with S-cone input. Two temporal frequencies are shown for each case. Fitted curves are derived from Naka-Rushton ${ }^{29}$ functions. Little evidence of response saturation is apparent. All cells and conditions show similar functions; intercell variability within a particular cell class and condition was comparable with the variability shown. Six s of data were averaged for each point. Fit parameters in impulses per second and percent contrast $\left(R_{\max }, b\right)$ are A, $1.22 \mathrm{~Hz}$ : 172.8 , 329.4; 9.76 Hz: 112.8, 69.4. B, $1.22 \mathrm{~Hz}: \quad 381.1$, 656.8; 9.76 Hz: 276.0, 257.5. C, $1.22 \mathrm{~Hz}: 140.8,107.1 ; 9.76 \mathrm{~Hz}$ : $273.0,211.5$ D, 1.22 Hz: $\quad 198.8,188.3 ; 9.76 \mathrm{~Hz}: \quad 284.9,250.4$. E, $1.22 \mathrm{~Hz}: \quad 89.2,70.3 ; 9.76 \mathrm{~Hz}: \quad 102.4,34.7 . \quad$ F, $1.22 \mathrm{~Hz}: \quad 402.5,519.8 ; 9.76 \mathrm{~Hz}:$ 216.0, 177.9. Values are in impulses per second and percent contrast for each pair of parameters..

cells and on M- and L-cone-opponent PC cells. Since these cells receive additive and subtractive $\mathrm{M}$ - and L-cone inputs, respectively, their responses give a measure of M- and L-cone modulation. The relative modulations of the red, green, and blue diodes were adjusted until cells of both types failed to respond. This stimulus was then used to modulate the $\mathrm{S}$ cones.

\section{B. Cone-Contrast Responses of Parvocellular Cells}

We recorded responses of 11 green-on $+\mathrm{M}-\mathrm{L}, 11$ redon $+\mathrm{L}-\mathrm{M}$, and $13+\mathrm{S}-(\mathrm{ML})$ cells as a function of temporal frequency and contrast. $\operatorname{Red}-o f f(-\mathrm{L}+\mathrm{M})$ and green-off $(-\mathbf{M}+\mathrm{L})$ cells were less frequently encountered but appeared to have temporal properties similar to those of their on counterparts. Data were also obtained from four cells with inhibitory S-cone inputs. Their responses appeared similar to those of $+\mathrm{S}-(\mathrm{ML})$ cells except for a reversal of response phase.

Figure 1 shows the first-harmonic response of typical PC cells plotted as a function of cone-modulation contrast. Two temporal frequencies are displayed for each condition. Higher cone contrasts can be achieved for the $\mathrm{S}$ cone than for the other two. Cell responses show a minor degree of response saturation at high conecontrast levels. We fitted the cone-contrast responses with Naka-Rushton ${ }^{29}$ functions, which provide a good description of the data. Parameters are given in the caption. All three cell types had similar contrast response functions. Differences among cells in Fig. 1 were within the range of intercell variability within the same class.

Response saturation is more marked in MC cells ${ }^{13,30}$ and is associated with operation of a contrast gain control not present in M-, L-cone-opponent PC-pathway cells. ${ }^{31,32}$ A characteristic feature of contrast gain control is a phase advance with increasing contrast. Figures $2 \mathrm{~A}$ and $2 \mathrm{~B}$ show the response phase as a function of cone modulation contrast for a $+\mathrm{S}-(\mathrm{L}+\mathrm{M})$ cell responding to $\mathrm{S}$-cone modulation and a red-on $+\mathrm{L}-\mathrm{M}$ cell responding to L-cone modulation. Response phase is independent of cone-modulation contrast in both cases. This result was observed at all temporal frequencies, for all PC cells and for all types of cone modulation. For comparison, in Fig. 3C the response phase of a MC cell with luminance modulation is shown to advance with increasing contrast 
over a frequency range (approximately 5-20 Hz) consistent with a contrast gain control as in the cat retina. ${ }^{33}$ Thus our data confirm the lack of a contrast gain control mechanism in M- and L-cone PC cells and show this also to be the case for cells with S-cone input.

In Fig. 3, we compare cone-contrast gain for cells with $+\mathrm{L}-\mathrm{M}$-cone input, $+\mathrm{M}-\mathrm{L}$-cone input, and S-cone input, together with standard errors of the measurements. The cone-contrast gain was defined as the initial slope of the Naka-Rushton function, as with the original definition of contrast gain for luminance modulation. ${ }^{33}$ All sets of data are of similar shape. Cone-contrast gain increases with frequency, reaches a peak between 10 and $20 \mathrm{~Hz}$, and then decreased rapidly. Similar temporal modulation-transfer functions are seen for all three cell types for both excitatory and inhibitory cone inputs. S-cone cells respond over a similar frequency range to M- and L-cone input cells. ${ }^{12}$

Figures $4 \mathrm{~A}, 4 \mathrm{~B}$, and $4 \mathrm{C}$ show mean response phase as a function of frequency for red-on $+\mathrm{L}-\mathrm{M}$-cone cells, green-on $+\mathrm{M}-\mathrm{L}$-cone cells, and S-cone input cells, respectively. For each cell the response phases for the three lowest contrasts for which first-harmonic amplitude
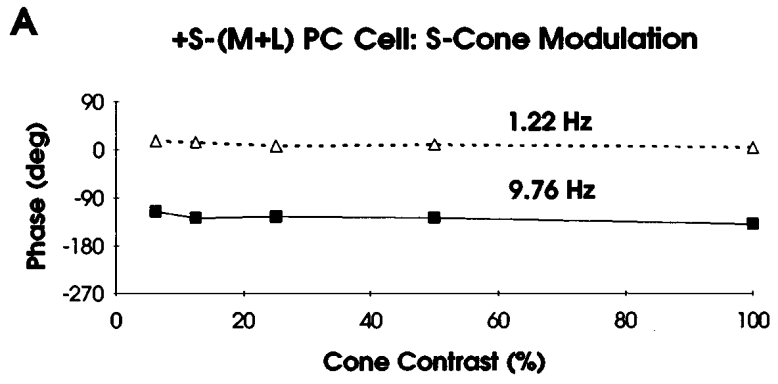

B

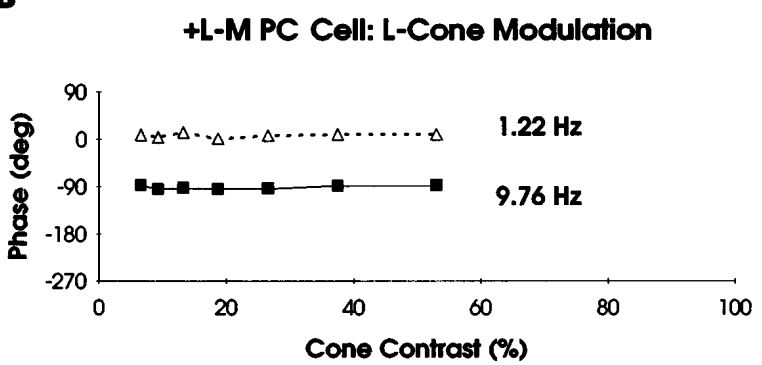

C

On MC Cell: Luminance Modulation

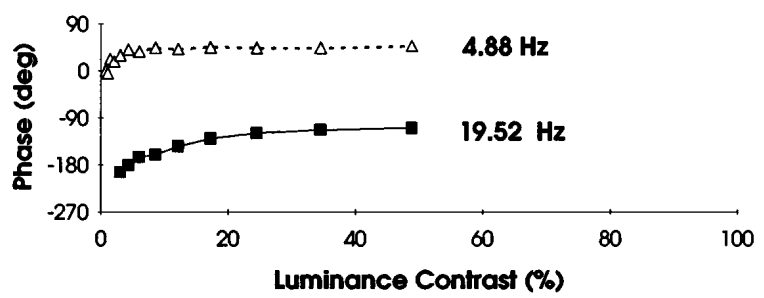

Fig. 2. Response phase as a function of modulation contrast for different cell types and conditions: A, B, Response phases of $\mathrm{a}+\mathrm{S}-(\mathrm{L}+\mathrm{M})$ cell for $\mathrm{S}-$ cone modulation and of $\mathrm{a}+\mathrm{L}-\mathrm{M}$ cell for L-cone modulation, at two frequencies in each case. Response phase is independent of cone contrasts. For comparison, $\mathrm{C}$ shows the response phase for a $\mathrm{MC}$ cell to luminance modulation, which shows a phase advance as contrast increases at both frequencies. exceeded $10 \mathrm{imp} / \mathrm{s}$ were averaged. At low frequencies, responses for excitatory and inhibitory cone inputs show a $180^{\circ}$ phase difference consistent with cone-opponent behavior. As frequency increased, this phase difference increased slightly for cells with only M- and L-cone input but not for those with S-cone input. The effect derives from a phase lag in the inhibitory cone consistent with a center-surround latency difference. The excitatory cone-response phase did not differ for the three cell types. In Fig. 5 we plot the phase difference among the cone responses as a function of frequency. Data collected at $40 \mathrm{~Hz}$ were not included in this analysis, because cell responses were sometimes weak and showed more variability at this frequency. We fitted a linear function to the results. The slopes were $1.79 \% \mathrm{~Hz}$ for $+\mathrm{L}-\mathrm{M}$-cone input cells and $0.45^{\circ} / \mathrm{Hz}$ for $+\mathrm{M}-$ L-cone input cells. This difference was significant at the $5 \%$ level. As a delay, it would correspond to $5.0 \mathrm{~ms}$ for $+\mathrm{L}-\mathrm{M}$ cells and $1.2 \mathrm{~ms}$ for $+\mathrm{M}-\mathrm{L}$ cells. In earlier results average delays of $7.4 \mathrm{~ms}^{23}$ and $9.5 \mathrm{~ms}^{34}$ for $+\mathrm{L}-\mathrm{M}$ cells and $4.0 \mathrm{~ms}^{23}$ and $3.9 \mathrm{~ms}^{34}$ for $+\mathrm{M}-\mathrm{L}$ cells were found. All three studies (obtained from nonoverlapping cell samples) suggest a slightly larger timing difference between excitatory and inhibitory cone inputs for $+\mathrm{L}-\mathrm{M}$ than for $+\mathrm{M}-\mathrm{L}$ cells. For cells with $\mathrm{S}$-cone input the slope was $0.25^{\circ} \mathrm{Hz}$, which was not statistically significant from zero ( $p>0.05, F$ test).

\section{Magnocellular Pathway Cell Responses}

For comparison with PC-cell data we recorded responses of 13 (5 on-, 8 off-center) MC cells to M- and L-cone modulation. A frequency-doubled response was seen in these cells with chromatic modulation, ${ }^{14}$ and a response at twice the stimulus frequency was also apparent with L- or M-cone modulation. These responses are illustrated in Fig. 6 for an off-center cell. Plots A and $\mathrm{B}$ show first- and second-harmonic amplitudes as a function of cone contrast for M- and L-cone modulation, respectively, at $9.8 \mathrm{~Hz}$. At low modulation depths the first harmonic response was the larger, but with increasing contrast a frequency-doubled response becomes apparent, and the second-harmonic came to exceed the first-harmonic in amplitude. Figure 6C shows a similar comparison for achromatic modulation for the same cell at the same frequency. Here, the proportion of second- to first-harmonic components remains constant as contrast increases and is associated with changes in response waveform rather than with a frequency-doubled response per se. Figure 6D shows similar data for M-cone modulation and $\mathrm{a}+\mathrm{M}-\mathrm{L} \mathrm{PC}$ cell. The secondharmonic component is small and again is associated with response shaping.

Frequency-doubled responses to M- or L-cone modulation were seen with all on- and off-center MC cells, especially at frequencies below $20 \mathrm{~Hz}$. This indicates that the nonlinearity cannot derive from a straightforward nonlinearity of cone summation, as originally proposed. ${ }^{14}$ If a rectifying or saturating nonlinearity at or before the site of cone summation occurred, then modulation of either the $\mathrm{M}$ or the $\mathrm{L}$ cone alone should not yield a frequencydoubled response.

We conclude that the MC-pathway-cell response to $\mathrm{M}$ - and L-cone modulation shows more evidence of 

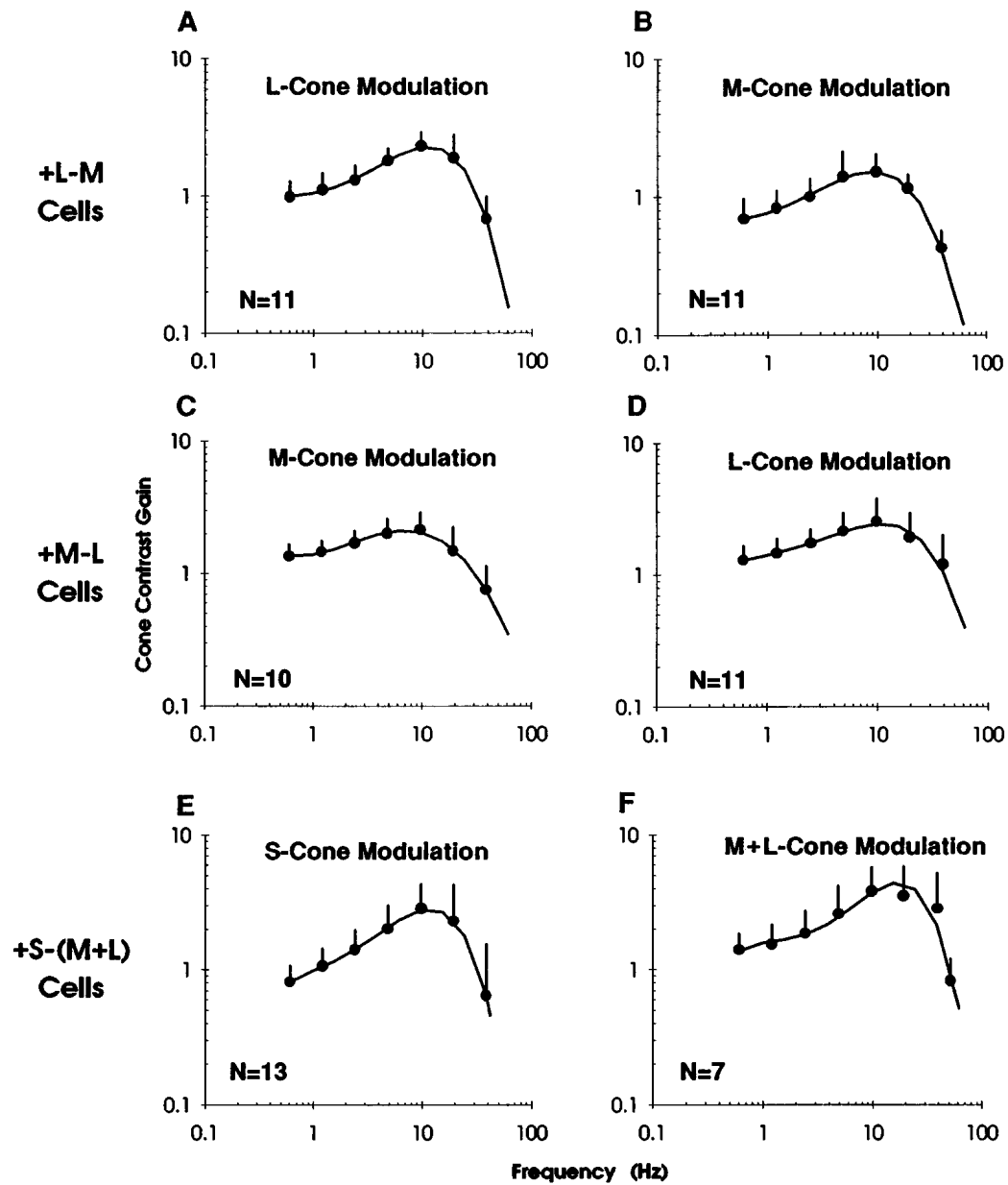

Fig. 3. Mean cone-contrast gain for different PC cells and conditions as a function of frequency: mean data for A, B, $+\mathrm{L}-\mathrm{M}-\mathrm{cone}$ cells; C, D, +M - L-cone cells; and E, F, S-cone input cells. Standard errors are shown for each data point. Solid curves, fitted fourth-order polynomials.
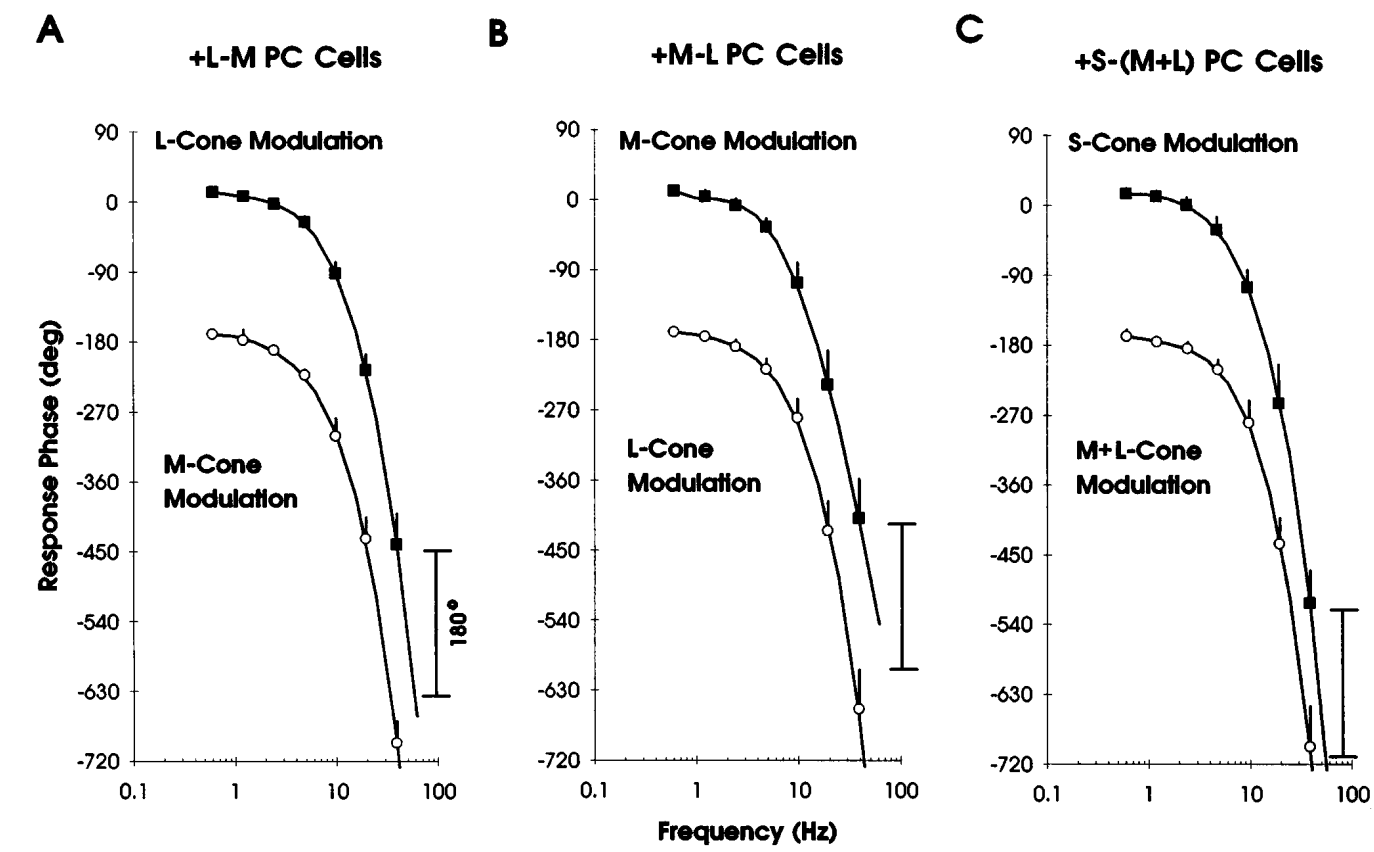

Fig. 4. Average response phase as a function of frequency. A, B, and C, Mean data from $+\mathrm{L}-\mathrm{M}$-cone cells, + M $-\mathrm{L}-\mathrm{cone}$ cells, and + S-cone cells, respectively. Squares, excitatory cone modulation; circles, inhibitory cone modulation; solid curves, fourth-order polynomial fits. At low frequency the response phase for the two sets of data in each panel differs by $180^{\circ}$. In A and B this difference increases slightly at high temporal frequency, as can be seen by referral to the $180^{\circ}$ references inserted at the bottom right in each panel. This was not the case for the S-cone cells. 

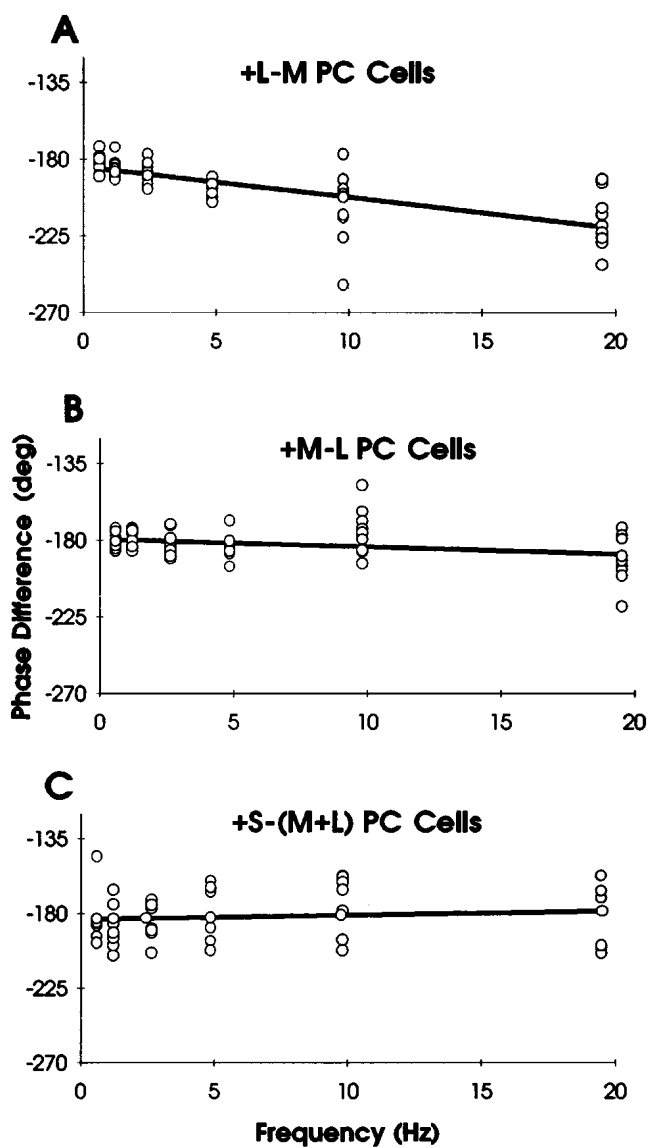

Fig. 5. Response phase differences for $\mathrm{A},+\mathrm{L}-\mathrm{M}$ cells; B, $+\mathrm{M}-\mathrm{L}$ cells, and $\mathrm{C},+\mathrm{S}$ cells as a function of frequency. Symbols represent individual cells' data. Least-squares linear regression lines have been fitted.

\section{A Off MC Cell: M-Cone Modulation}

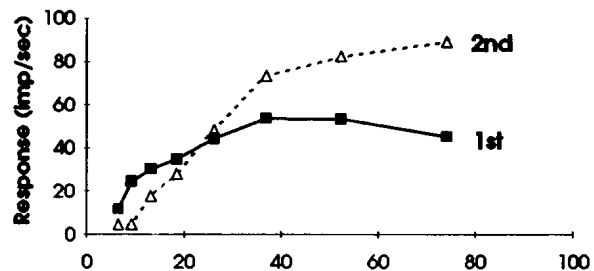

C Off MC Cell: Luminance Modulation

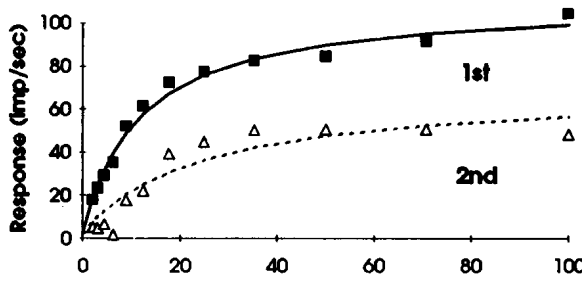

modification of the receptor signal than is the case with PC-pathway cells.

\section{Psychophysical Sensitivity to Modulation} along a Tritanopic Confusion Line

S-cone excitatory cells responded up to at least $40 \mathrm{~Hz}$, which is a much higher frequency than was suggested by earlier psychophysics. ${ }^{35}$ For comparison with the physiological data, we measured psychophysical sensitivity to temporal modulation of the $\mathrm{S}$ cone. Figure 7A shows results for four observers; the results are displaced vertically for clarity. Their sensitivity functions show low-pass characteristics, with interobserver variation in cutoff frequency. The data resemble the S-cone modulation sensitivity functions reported by Wisowaty and Boynton $^{35}$ and data collected at moderate S-cone adaptation levels by Stockman et al. ${ }^{6}$ S-cone-cell contrast gains are included for comparison and are seen to extend to much higher temporal frequencies.

Psychophysical-to-physiological sensitivity ratios are plotted in Fig. 7B. Ratios decrease rapidly at high frequencies, and we assume this to represent a central filter characteristic. We fitted four-stage linear filters to the data with a least-mean-squares procedure. Corner frequencies (to half-amplitude) varied from 2.8 to $5.0 \mathrm{~Hz}$ depending on the observer. Using filters with different numbers of stages did not significantly improve the goodness of fit. These corner frequencies are comparable with but slightly lower than those derived in previous studies in which red-green chromatic modulation was used. $^{13,36}$ It should be noted that in those studies corner frequency was expressed as the reciprocal of the filter time constant.

\section{B Off MC Cell: L-Cone Modulation}

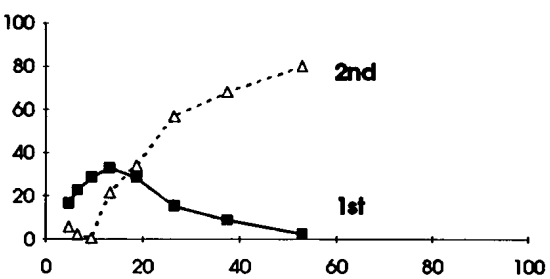

\section{D +M-L PC Cell: M-Cone Modulation}

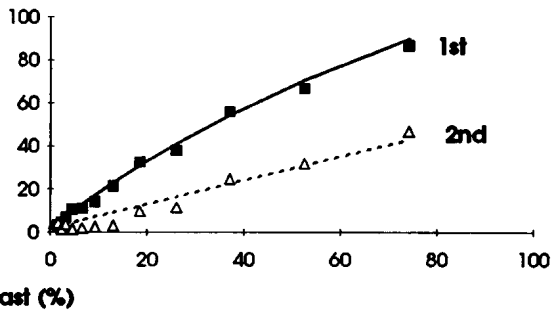

Fig. 6. Cone-contrast response functions for $\mathrm{MC}$ cells at $9.8 \mathrm{~Hz}$. A, B, First- and second-harmonic amplitudes of responses to M- and L-cone modulation for an off-center MC cell. As contrast is increased, a large second-harmonic response becomes apparent and eventually exceeds the first-harmonic response in amplitude. C, First- and second-harmonic responses of the same MC cell to luminance modulation; the proportion of second to first harmonic remains constant and is associated largely with response shaping rather than with a frequency-doubled response. D, First- and second-harmonic responses of $+\mathrm{M}-\mathrm{L}$ cell to M-cone modulation; second-harmonic components are restricted in amplitude. Fit parameters are C, 108.8, 11.9; D, 273.0, 211.5. Values are in impulses per second and percent contrast for each pair of parameters. 

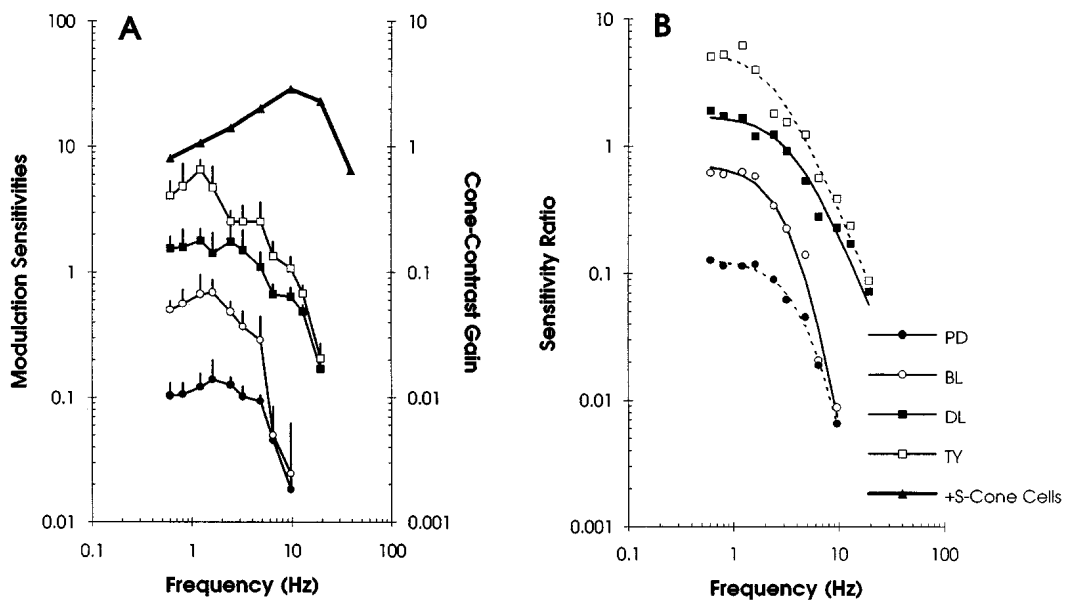

Fig. 7. Comparison of S-cone temporal responsivity in PC cells with psychophysical S-cone temporal sensitivity of human observers. A, Temporal modulation sensitivity function for four observers and mean data from PC cells with excitatory cone input. For clarity, the data have been scaled vertically. B, Psychophysical-to-physiological ratios for S-cone modulation. Data from the four observers have been shifted vertically for clarity by the following amounts: PD, unshifted, BL, 0.5 log unit; DL and TY, 1.0 log unit. Continuous curves, least-square fits of four-stage low-pass filters to the data.

\section{DISCUSSION}

The time course of responses of individual receptors to brief light pulses was measured by Schnapf et al. ${ }^{8}$ We derived pulse responses from our data to compare with receptor responses using a Fourier expansion. ${ }^{32}$ Pulse responses were similar in shape to those of Schnapf et $a l{ }^{8}$ Time to peak over cell groups and stimulus conditions ranged from 30 to $36 \mathrm{~ms}$. This is slightly faster than recordings from the individual receptors, which gave times to peak of $\sim 50 \mathrm{~ms}$. Pulse responses to activation of the $\mathrm{M}$ and the $\mathrm{L}$ cones derived from white-noise analysis ${ }^{10}$ are slightly slower than those that we derived, although retinal illuminance may have been lower in these earlier measurements. The reason for these discrepancies is unclear, but they are minor.

If there were a significant mixed cone input to the surrounds of PC cells with only M- and L-cone input, ${ }^{37}$ temporal sensitivity would be expected to be more bandpass in shape with the center cone mechanism, because of the interaction of the same cone in center and surround with a surround delay. This occurs with luminance modulation. ${ }^{12}$ Also, an interaction of cone weighting with frequency might be expected. These effects were not observed, although a small amount of mixing would be difficult to detect. Nevertheless, the cumulative evidence ${ }^{23,38}$ seems contrary to the hypothesis of mixed cone input to the surround mechanisms of $\mathrm{M}$-, L-cone PC cells.

Any differences in temporal properties of cone inputs to PC cells in the present data are much smaller than those suggested by Gouras and Zrenner. ${ }^{39}$ These earlier studies attempted to isolate cone responses by luminance modulation of light of different wavelengths, so that adaptation state varied substantially among different conditions. Our data, obtained under fixed adaptation conditions and with more complete isolation of cone responses, showed much smaller differences between temporal properties in PCpathway cells.
If all three cones have similar temporal properties at the level of the PC-pathway ganglion cell, earlier psychophysical evidence for poor temporal resolution in the Scone pathway ${ }^{3,4,40}$ is thus a result of postretinal filtering. If the effect of this filtering is avoided, the S-cone system can be shown to respond up to $\sim 40 \mathrm{~Hz}{ }^{6,7}$ The comparison of psychophysical and physiological S-cone temporalsensitivity functions may reveal the characteristic of the low-pass filter acting upon PC-pathway signals. Taking the ratio of physiological to psychophysical data provides a measure independent of assumptions as to how psychophysical thresholds relate to single-cell responsivities, provided that the S-cone signal does not become noisier with increasing temporal frequency. We tested whether the increased variability in response phase at high frequency could account for the psychophysical results, ${ }^{13}$ but this was not the case.

Our analysis indicated corner frequencies of a central filter between 2.8 and $5 \mathrm{~Hz}$, depending on the observer. A similar filter acts upon the red-green pathway, earlier estimated to have a corner frequency (to half-amplitude) of $\sim 7 \mathrm{~Hz} \cdot{ }^{13}$ This earlier estimate may have been high as a result of possible intrusion of the MC pathway into detection of red-green modulation. In another study a comparison of PC-pathway and human observers' responses to complex chromatic waveforms also suggested operation of a low-pass filter with a corner frequency (to half-amplitude) of $3.5-7 \mathrm{~Hz}^{36}$ It seems likely that the same filter acts upon all PC-pathway signals independently of adaptation level and stimulus conditions. It has been proposed that S-cone modulation may be detected through both chromatic and luminance mechanisms, ${ }^{6}$ but we did not distinguish between these mechanisms in the current experiments.

Finally, we stress that the temporal properties of the $\mathrm{M}$ and the $\mathrm{L}$ cones seem similar when measured from PC-cell responses. On the basis of psychophysical data measuring critical fusion frequency with red and green lights, Hamer and Tyler suggested that the $\mathrm{M}$ cone may be faster. ${ }^{11}$ We have replicated their results in MC cells. ${ }^{41}$ It is possible that adaptation state 
changes in the flicker fusion experiments may have some additional effect.

There has been speculation that latency difference among cone inputs to PC-pathway cells might give rise to illusory colors, as in Benham's top. ${ }^{42}$ In our data a slightly longer surround delay in red-on compared with that in green-on cells was the only difference observed. No difference was found with cells with S-cone input. Whether the surround difference in red-green cells would be adequate to generate illusory colors is unclear. One recent model ${ }^{42}$ attempted to use physiological delays in a plausible range, but the differences that we observed in the timing of the cone signals in PC-cell responses were not in a direction consistent with the assumptions of this model.

\section{ACKNOWLEDGMENTS}

We thank Joel Pokorny and Vivianne Smith for discussion of the results. T. Yeh was partially supported by Deutsche Forschungsgemeinschaft grant II B 7-Le 524/8-1.

*Present address, Department of Biomedical Engineering, Northwestern University, Evanston, Illinois.

${ }^{\dagger}$ Present address, Department of Experimental Ophthalmology, University of Tübingen, Germany.

\section{REFERENCES}

1. O. Estévez and H. Spekreijse, "A spectral compensation method for determining the flicker characteristics of human colour mechanisms," Vision Res. 14, 823-830 (1974).

2. G. S. Brindley, J. J. du Croz, and W. A H. Rushton, "The flicker fusion frequency of the blue-sensitive mechanism of colour vision," J. Physiol. (London) 183, 497-500 (1966).

3. D. G. Green, "Sinusoidal flicker characteristics of the colorsensitive mechanisms of the eye," Vision Res. 9, 591-601 (1969).

4. D. H. Kelly, "Spatio-temporal frequency characteristics of color-vision mechanisms," J. Opt. Soc. Am. 64, 983-990 (1974).

5. D. H. Kelly and D. van Norren, "Two-band model of heterochromatic flicker," J. Opt. Soc. Am. 67, 1081-1091 (1977).

6. A. Stockman, D. I. A. MacLeod, and D. D. DePriest, "The temporal properties of the human short-wave photoreceptors and their associated pathways," Vision Res. 31, 189-208 (1991).

7. A. Stockman, D. I. A. MacLeod, and S. J. LeBrun, "Faster than the eye can see: blue cones respond to rapid flicker," J. Opt. Soc. Am. A 10, 1396-1402 (1993).

8. J. L. Schnapf, B. J. Nunn, M. Meister, and D. A. Baylor, "Visual transduction in cones of the monkey Macaca fascicularis," J. Physiol. 427, 681-713 (1990).

9. E. Zrenner and P. Gouras, "Characteristics of the blue sensitive cone mechanism on primate retinal ganglion cells," Vision Res. 21, 1605-1609 (1981).

10. C. C. A. M. Gielen, J. A. M. van Gisbergen, and A. J. H. Vendrik, "Reconstruction of cone-system contributions to responses of colour-opponent neurons in monkey lateral geniculate," Biol. Cybern. 44, 211-221 (1982).

11. R. D. Hamer and C. W. Tyler, "Analysis of visual modulation sensitivity. V. Faster visual response for G- than for R-cone pathway?" J. Opt. Soc. Am. A 9, 1889-1904 (1992).

12. B. B. Lee, P. R. Martin, and A. Valberg, "Sensitivity of macaque retinal ganglion cells to chromatic and luminance flicker," J. Physiol. (London) 414, 223-243 (1989).

13. B. B. Lee, J. Pokorny, V. C. Smith, P. R. Martin, and A. Valberg, "Luminance and chromatic modulation sensitivity of macaque ganglion cells and human observers," J. Opt. Soc. Am. A 7, 2223-2236 (1990).

14. B. B. Lee, P. R. Martin, and A. Valberg, "Nonlinear summa- tion of M- and L-cone inputs to phasic retinal ganglion cells of the macaque," J. Neurosci. 9, 1433-1442 (1989).

15. W. H. Swanson, T. Ueno, V. C. Smith, and J. Pokorny, "Temporal modulation sensitivity and pulse-detection thresholds for chromatic and luminance perturbations," J. Opt. Soc. Am. A 4, 1992-2005 (1987).

16. A. Valberg, B. B. Lee, P. K. Kaiser, and J. Kremers, "Responses of macaque ganglion cells to movement of chromatic borders," J. Physiol. 458, 579-602 (1992).

17. T. Yeh, B, B. Lee, and J. Kremers, "Temporal contrast sensitivities measured in retinal parvocellular cells of the macaque," Perception 21, Suppl. 2, 9 (1992).

18. D. B. Judd, "Colorimetry and artificial daylight," in Technical Committee No. 7 Report of Secretariat United States Commission, International Commission on Illumination, Twelfth Session (International Commission on Illumination, Stockholm, 1951), pp. 1-60.

19. G. Westheimer, "The Maxwellian view," Vision Res. 6, 669-682 (1966).

20. V. C. Smith and J. Pokorny, "Spectral sensitivity of the foveal cone photopigments between 400 and $500 \mathrm{~nm}$," Vision Res. 15, 161-171 (1975).

21. R. M. Boynton and N. Kambe, "Chromatic difference steps of moderate size measured along theoretically critical axes," Color Res. Appl. 5, 13-23 (1980).

22. D. I. A. MacLeod and R. M. Boynton, "Chromaticity diagram showing cone excitation by stimuli of equal luminance," J. Opt. Soc. Am. 69, 1183-1185 (1979).

23. V. C. Smith, B. B. Lee, J. Pokorny, P. R. Martin, and A. Valberg, "Responses of macaque ganglion cells to the relative phase of heterochromatically modulated lights," J. Physiol. 458, 191-221 (1992).

24. B. B. Lee, A. Valberg, D. A. Tigwell, and J. Tryti, "An account of responses of spectrally opponent neurons in macaque lateral geniculate nucleus to successive contrast," Proc. R. Soc. London Ser. B 230, 293-314 (1987).

25. B. B. Lee and T. Yeh, "Tritan pairs estimated by modulation photometry of red, green, and blue lights," in Colour Vision Deficiencies XII, B. Drum. ed. (Kluwer, Dordrecht, The Netherlands, to be published).

26. A. Valberg and B. W. Tansley, "Tritanoptic purity-difference function to describe the properties of minimally distinct borders," J. Opt. Soc. Am. 67, 1330-1336 (1977).

27. J. K. Bowmaker, "Visual pigments and color vision in primates," in From Pigments to Perception, A. Valberg and B. B. Lee, eds. (Plenum, New York, 1991), pp. 1-10.

28. D. A. Baylor, B. J. Nunn, and J. L. Schnapf, "Spectral sensitivity of cones of the monkey Macaca Fascicularis," J. Physiol. 390, 145-160 (1987).

29. K. I. Naka and W. A. Rushton, "S-potentials from colour units in the retina of fish (Cyprinidae)," J. Physiol. (London) 185, 536-555 (1966).

30. E. Kaplan and R. M. Shapley, "The primate retina contains two types of ganglion cells with high and low contrast sensitivity,” Proc. Natl. Acad. Sci. USA 83, 2755-2757 (1986).

31. E. A Benardete, E. Kaplan, and B. W. Knight, "Contrast gain control in the primate retina: $\mathrm{P}$-cells are not X-like, some M-cells are," Visual Neurosci. 8, 483-486 (1992).

32. B. B. Lee, J. Pokorny, V. C. Smith, and J. Kremers, "Responses to pulses and sinusoids in macaque ganglion cells," Vision Res. 34, 3081-3096 (1994).

33. R. M. Shapley and J. D. Victor, "The effect of contrast on the transfer properties of cat retinal ganglion cells," J. Physiol. 285, 275-298 (1978).

34. B. B. Lee, P. R. Martin, A. Valberg, and J. Kremers, "Physiological mechanisms underlying psychophysical sensitivity to combined luminance and chromatic modulation," J. Opt. Soc. Am. A 10, 1403-1412 (1993).

35. J. J. Wisowaty and R. M. Boynton, "Temporal modulation sensitivity of the blue mechanism: measurements made without chromatic adaptation," Vision Res. 20, 895-909 (1980).

36. J. Kremers, B. B. Lee, J. Pokorny, and V. C. Smith, "Responses of macaque ganglion cells and human observers to compound periodic waveforms," Vision Res. 33, 1997-2011 (1993).

37. P. Lennie, P. W. Haake, and D. R. Williams, "The design of 
chromatically opponent receptive fields," in Computational Models of Visual Processing, M. S. Landy and J. A. Movshon, eds. (MIT Press, Cambridge, Mass., 1991), pp. 71-82.

38. R. C. Reid and R. M. Shapley, "Spatial structure of cone inputs to receptive fields in primate lateral geniculate nucleus," Nature (London) 356, 716-718 (1992).

39. P. Gouras and E. Zrenner, "Enhancement of luminance flicker by color-opponent mechanisms," Science 205, 587-589 (1979).

40. T. Uetseki and M. Ikeda, "Adaptation and critical duration for Stiles $\pi$ mechanisms," J. Opt. Soc. Am. 61, 821-828 (1971).
41. J. Pokorny, V. C. Smith, B. B. Lee, and T. Yeh, "Temporal sensitivity of macaque ganglion cells to lights of different chromaticities," Invest. Ophthalmol. Vis. Sci. Suppl. 35, 2126 (1994).

42. S. M. Courtney and G. Buchsbaum, "Temporal differences between color pathways within the retina as a possible origin of subjective colors," Vision Res. 31, 1541-1548 (1991). 